DOI: 10.20472/IAC.2018.039.011

\author{
FARUK DAYI \\ KASTAMONU UNIVERSITY, Turkey \\ IBRAHIM YASAR GOK \\ SULEYMAN DEMIREL UNIVERSITY, Turkey \\ TOLGA ULUSOY \\ Kastamonu University, Turkey
}

\title{
THE RELATIONSHIP BETWEEN FOOTBALLER AND HEAD COACH TRANSFER NEWS AND STOCK PRICES OF SPORT CLUBS
}

\begin{abstract}
:
Sportive performances of sports clubs are closely pursued by investors and the effect of match results on stock prices are widely investigated in the literature. On the other hand, whatever the results of the matches might be, the football players and head coaches affect the game by their physical performances, abilities, intelligence and strategic thinking characteristics. Football players and head coaches are the most important assets of the clubs that they work for. Nevertheless, the impact of transfer news of football players and head coaches on the clubs' stock prices have rarely been studied. We aimed to analyze the effects of transfer news of Trabzonspor (TSPOR: Istanbul), one of the four sports clubs traded in Borsa Istanbul, on stock prices within the scope of this study. The transfers exceeding a capital of 1 million Euros during the period of 2013-2017 were investigated by event study analysis. By analyzing 47 events related to football players and 15 events to head coaches, it was found that the contract news of head coaches had more prominent effects on returns than that of footballers'.
\end{abstract}

\section{Keywords:}

Sport clubs, transfer news, stock prices, event study analysis

JEL Classification: L83, G12, G14 


\section{Introduction}

Sports clubs appear in national and international leagues and tournaments. They may play more than one game during the course of a week, may attain league championships with respect to their match results, may win various national and international cups or may be eliminated from such cups. Results of the matches, therefore, have a direct impact on the club's financial performance. This impact on financial performance either appears in the form of impact on financial statements or on the stock prices of clubs.

It is expected that companies' success in realizing its activities would be reflected in their financial statements. Within the context of fundamental analyses, it is also natural to expect sports club investors to be focused on the companies' financial performance. According to the Club Licensing Benchmarking Report of the Union of European Football Associations (UEFA) for the financial year of $2016,34 \%$ of club revenues were found to be generated from publishing revenues, $24 \%$ from sponsorship agreements, $15 \%$ from box-office revenues, $10 \%$ from UEFA and $9 \%$ from commercial sales activities (UEFA, 2018). There exists a positive correlation between clubs' sportive performance and the abovementioned revenue items. There will be a high cash flow for instance, for a team that wins the UEFA Champions League Cup or that qualifies for the next round due to its success on the field. Indeed, 2016-2017 UEFA Champions League Winner, Real Madrid earned $€ 6$ million for qualifying for the last 16 in UEFA (round of 16), $€ 6.5$ million for qualifying for quarterfinals, $€ 7.5$ million for semi-finals and $€ 15.5$ million for the finals. (Total Sportek, 2018). By the same token, following merits were rewarded to the clubs with respect to their positions in La Liga during the season of 2016-2017: $€ 20.8$ million for champion Real Madrid , $€ 18.3$ million to Barcelona for the second place, $€ 15.9$ million to Atletico for the third place, $€ 13.4$ million to Sevilla for the fourth place, and $€ 11$ million to Villarreal for the fifth place (Goal.com, 2017). On the other hand, teams that fail might experience a decline in their revenues, thus also in their profits. As a matter of fact, Arsenal's failure of not being able to attend 2016-2017 UEFA Champions League resulted in a decline to an extent of more than $60 \%$ in the team's operating profit (The Telegraph, 2018). Based on the study they conducted on La Liga, Barajas et al. (2005), found that the sportive performance explained $55.12 \%$ of the variance in revenues.

Whereas the second aspect related to results of match results might appear in the context of stock markets in the form of stock prices of clubs. Zuber et al. (2005) stated that the profit and transaction volume of sports clubs traded in the English Premier League were not sensitive to match results, which would mean that the investor-fans were not making interactions regarding information which might affect cash flow. Analyzing 1274 matches of eight teams in five countries of Europe, Scholtens and Peenstra (2009) found out that the share market had a significantly positive reaction regarding wins and a significantly negative reaction regarding defeats; moreover that the reaction was greater for European competitions than it was for local games. Bell et al. (2012) proved that the important games played by English Premier League teams 
affected stock prices more than the less important ones. Zeren and Gümüş (2013) analyzed the relationship between game results of 8 European clubs -4 of which were from Turkey- within the period between 2007-2011 and corresponding stock market performances; and reported that the wins had an effect for Galatasaray Club's stock prices, whereas the defeats affected stock prices of Fenerbahce, Juventus, Roma and Borussia Dortmund teams. Uludağ and Sigalı (2016) found evidence that ties and defeats of four sports clubs publicly traded during the seasons 2009-2013 had an effect on stock prices, however, that this effect was not on the same level for all of the teams, and further that the investor behavior might not be rational. Godinho and Cerqueira (2018) conducted an analysis by first placing weights on matches of thirteen teams from six European countries according to the games' importance and than setting out unexpected components of the games for the ones whose pre-game predictions were different from the result of the game; and found out that a significant relationship existed between the game results and the stock market performance for most of the teams.

It might be a better approach not to investigate direct effects of game results but to investigate effects of deviations from the expected results based on bets. Because with the utilization of such a method, an unexpected -i.e, surprise- case's pricing would be in question. On the other hand, despite the potential effect of game results on both financial statements and on stock market performance, the main factors determining the game results are the players' performances and the game strategies' of head coaches. There is a differentiation between sports companies and other companies. And this differentiation results from the fact that the player and head coaches being the main elements leading these companies, being the most valuable assets of these companies where the major expense item is the money spent on them, and their physical performance being the major contributing factor to the companies' worth. Therefore human resources of these companies affect the financial performance of the company to an extent that no other company experiences. By the same token, football players and technical staff are of utmost importance for sports clubs. Yet the cases of early public acknowledgment of negotiations with footballers' and coaches' for taking a part in the team, the announcement of coming to an agreement with them or dissolution of contracts of coaches during the season are not expected events. Within this framework, it might be considered that these cases might as well be priced by investors. However, investigation of such cases' effects on stock market performance is observed to be rarely studied.

Effect of in-season coach replacement on the teams' sportive performance was empirically considered in numerous studies. De Dios Tena and Forrest (2007) came to a conclusion that the in-season dismissal of head coaches led to an increase in team's performance and the infield performance of teams improved after the replacement in La Liga. Heuer et al. (2011) proved that the in-season head coach replacement did not lead to a general change in team's performance in Bundesliga. González-Gómez et al. (2011) found out that the head coach replacements improved sportive performance, however, that the performance of such teams was not in level with the ones that did 
not experience a replacement in La Liga. On the other hand, despite the investigation of effects on sportive success through such studies, a direct effect of these cases on stock market performance was found to be rarely studied. Whereas the effect of a company's CEO's dismissal on the companies stock prices was found to be investigated in numerous studies ${ }^{1}$. There is thus no theoretical hindrance regarding the football clubs for analyzing the effects of head coach dismissal with respect to investors. As a matter of fact, one of the few studies within this context was conducted by Bell et al. (2013). In their study, where dismissals or resignations of 53 executives of British clubs during 9 seasons were investigated, it was determined that dismissals led to an increase in stock prices, whereas resignations led to a decrease.

A similar situation holds also true for transfer news of football players. Corresponding market reaction to this public information was rarely considered as a research topic within the context of literature. One of the few studies regarding this subject belongs to Fotaki et al. (2009). These researchers revealed a negative investor reaction to buying of players for United Kingdom Football Clubs, whereas player sales resulted in a positive investor reaction. In their study where factors affecting revenues and volatilities of 24 clubs that were publicly traded was investigated for 9 seasons, Gimet and Montchaud (2016) found out that the transfer news significantly affected volatilities, though they did not have any effect on revenues.

Soccer is the most important sports activity in Turkey. Especially Galatasaray, Fenerbahçe, Besiktaş and Trabzonspor, also called as the big four each have millions of supporters, and these clubs are also publicly traded. Turkey Football Federation's Super League comprises of 18 teams, with the League's total market value being $€ 669.13$ million as of April 2018. Trabzonspor's transfer expenditure, on the other hand, summed up to $€ 15.6$ million for the 2017-2018 season (TransferMarkt, 2018). Having a transfer expenditure of $€ 95$ million for the year 2017, and a $€ 80$ million transfer revenue, Turkey is one of the 10 most active markets among all the transfer markets in Europe (UEFA, 2018). Whereas it is important to note here that, there has been a dramatical decline in the clubs' transfer expenditures due to UEFA's financial fair play enforcements.

Being one of the four publicly traded sports clubs in Borsa Istanbul, effect of Trabzonspor's transfer of 47 football players with a transfer or an annual fee over $€ 1$ million along the four seasons during 2013-2017 on stock prices was investigated along with the effect of 15 head coach agreements or contract terminations during the same period in this study, via event analysis method. This study is one of the few studies that can be found in the literature regarding the effect of sports clubs' human resources on stock prices. Moreover, the subject is addressed for the very first time with respect to sports clubs in Turkey.

${ }^{1}$ (see Dedman will start calling and Lin, 2002; Kind and Schläpfer, 2010; Farah et al., 2015) 
The study proceeds with information on data and methodology along the second section, whereas the 3rd section includes empirical findings, with a consequent summary of the study in conclusions section.

\section{Data and Methodology}

Effect of news (events) related to Trabzonspor Club's (TSPOR) football player transfers or head coach replacements during the period 2013-2017 with respect to returns in TSPOR stock was investigated in the study. Two different datasets were created in order for determining the effect of football player- and coach-related news on stock returns. A total of 126 events, with 110 being related to football players, and 16 related to head coaches was collected by making use of information published on Public Disclosure Platform (CAP). Considering that it would not be possible for all football related news to have an effect on stock returns, only the events with a transfer fee or an annual fee of $€ 1$ million and above were included in the data set. Coach related news was all to be included in the analysis at first, however since one event could not be included due to a problem of defining its date accurately, 15 events in total were included in the analysis. Data related to football player transfer events are provided in Table 1.

Table 1: Distribution of Football Player Transfer Events

\begin{tabular}{l|c|c|c|c|c|c}
\hline \hline Football player & $\mathbf{2 0 1 3}$ & $\mathbf{2 0 1 4}$ & $\mathbf{2 0 1 5}$ & $\mathbf{2 0 1 6}$ & $\mathbf{2 0 1 7}$ & Total \\
\hline \hline Transfer Fee (Buying) & 2 & 13 & 7 & 8 & 8 & 38 \\
\hline Transfer Fee (Sales) & 1 & 5 & 0 & 0 & 0 & 6 \\
\hline Termination of Contract & 0 & 3 & 0 & 0 & 0 & 3 \\
\hline Total & $\mathbf{3}$ & $\mathbf{2 1}$ & $\mathbf{7}$ & $\mathbf{8}$ & $\mathbf{8}$ & $\mathbf{4 7}$ \\
\hline
\end{tabular}

Source: Own

As can be observed in Table 1, football player events can be categorized into three categories such as buying of license, sales of license and contract termination. Temporary transfers and temporary leasing options of football players were considered under the heading of either Buying or Sales of transfer fees. Football players that did not renew their contracts were not included in the study since exact information related to them was not present. Analyzing the 5-year-period, it was seen that the highest football player transfer events occurred in the year of 2014, whereas the least occurred in the year of 2013. Yearly distribution of events related to coaches is given in Table 2 . 
Table 2: Distribution of Head Coach Related Events

\begin{tabular}{l|c|c|c|c|c|c}
\hline \hline Head Coach Replacement & $\mathbf{2 0 1 3}$ & $\mathbf{2 0 1 4}$ & $\mathbf{2 0 1 5}$ & $\mathbf{2 0 1 6}$ & $\mathbf{2 0 1 7}$ & Total \\
\hline \hline Signing the Contract & 2 & 3 & 1 & 1 & 1 & 8 \\
\hline Contract Termination & 1 & 2 & 2 & 1 & 1 & 7 \\
\hline Total & $\mathbf{3}$ & $\mathbf{5}$ & $\mathbf{3}$ & $\mathbf{2}$ & $\mathbf{2}$ & $\mathbf{1 5}$ \\
\hline
\end{tabular}

Source: Own

Data related to head coach replacement is provided in Table 2, under two headings: namely, signing of the contract and contract termination. By inspecting Table 2, it can be seen that a total of 15 events are present during the course of 5 years, 8 of which related to sign of contract and 7 related to contract termination. Events related to the football players and head coaches were utilized for event study analyses.

Event study analysis was first conducted in 1933, by James Dolley (MacKinlay, 1997:13). Whereas the methodology for event study analysis was developed by Fama, Fisher, Jensen and Roll in 1969 (Binder, 1998: 111). Event study analysis is used to measure a stock's reaction to certain events or notifications (Binder, 1998: 111). Since the reaction given by the stock to events that are not ordinary might lead to abnormal yields. (Serra, 2004: 2). Therefore any negative or positive changes regarding the price of stocks have a direct effect on the value of shareholders' partnership shares (Bechetti et al., 2007:1-8). By using event analysis, the mentioned effect can be assessed. Event analysis comprises of calculating the change in the return of the stock is by comparing its value on the days before and after the occurrence of an event (Dyckman et al., 1984). Data belonging to the day prior to the event should be used for calculating the return of the stock on the day the event occurred. For this reason, returns for 11, 16 and 21 days were calculated for the purposes of the study, since the calculations were based on data belonging to one day prior to the event. Abnormal returns of stock were calculated by the following formula for event study analysis (Peterson, 1989: 45):

$$
A R=\frac{1}{N} \sum_{1}^{N} e_{i t}
$$

Return of stock was denoted by "e", the day of the event was denoted by "t", the period was denoted by "N", and the number of events was denoted by "i". Average returns of the stock were calculated by taking 10, 15 and 20-day periods used for analyses into account. Cumulative average return of events were calculated by making use of the following formula:

$$
\operatorname{CAR}\left(t_{1}, t_{2}\right)=\frac{1}{N} \sum_{t=t_{1}}^{t_{2}} A R_{t}
$$


Average returns of $t_{1}$ event and $t_{2}$ periods were calculated and their cumulative sums were subsequently taken. So that the total effect of events on the stock returns was calculated. Statistical significance of returns was evaluated by using the t-test.

\section{Empirical Findings}

10,15 and 20-day-return data for TSPOR stock during the period of 2013-2017 was utilized for the event study analyses conducted for the purposes of this study. Separate analyses were performed for head coach related and football player related news and corresponding results were evaluated.

\subsection{Event Analyses Results of Transfer of Football Players}

The 10-day impact of player transfer news on TSPOR stock is depicted in Figures 1 and 2. It can be observed that returns tended to lie in a positive direction for the period of 10 days before and 10 days after the transfer news. It was determined that the investors tended to enter an expectant state after hearing the transfer news and also that the returns increased more during that period.

Figure 1: Returns 10 Days Before News

Figure 2: Returns 10 Days After News

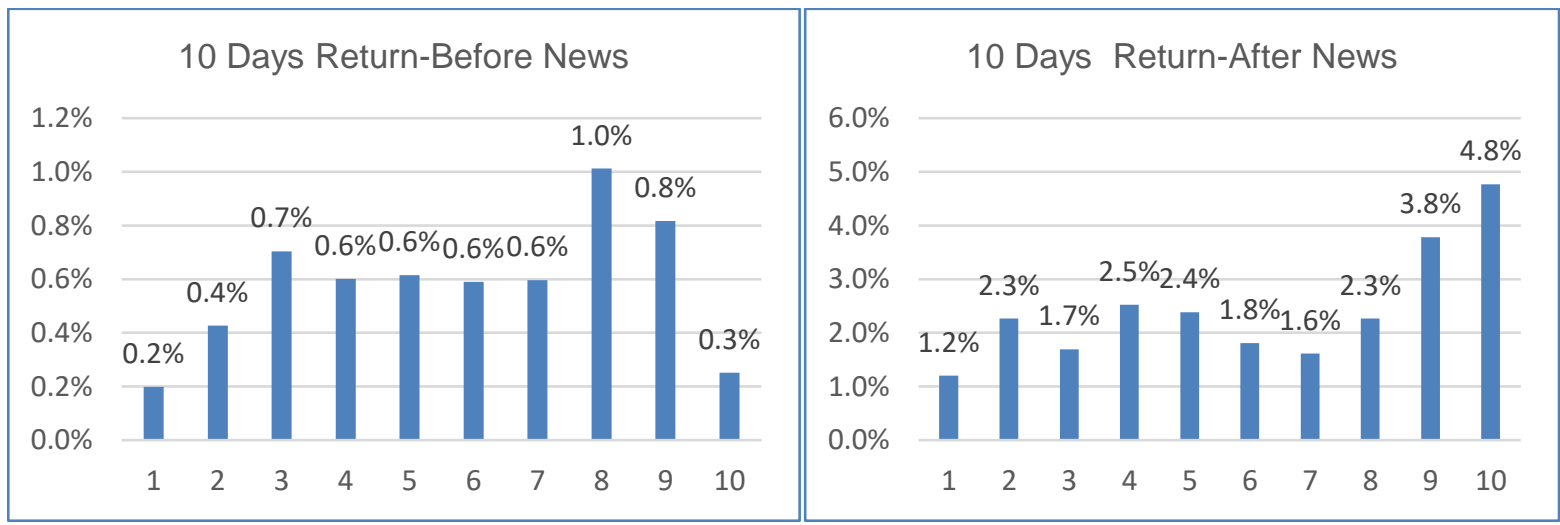

Source: Own

Source: Own

The 15-day impact of player transfer news on TSPOR stock is depicted in Figures 3 and 4. It can be observed that the values of returns fifteen days before the news were negative, except for the value of the first day. Even though the returns may be negative, the highest loss was observed on the 5th day, with a value of $-1.1 \%$. Moreover, despite the positive direction of returns on the first day, the value of the return was observed to be only $0.1 \%$. 
Figure 3: Returns 15 Days Before News

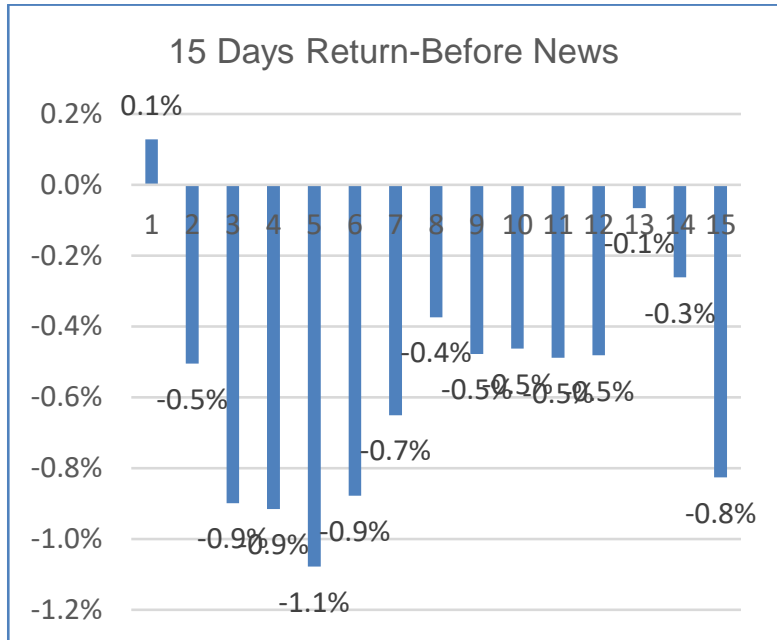

Source: Own

\section{Figure 4: Returns 15 Days After News}

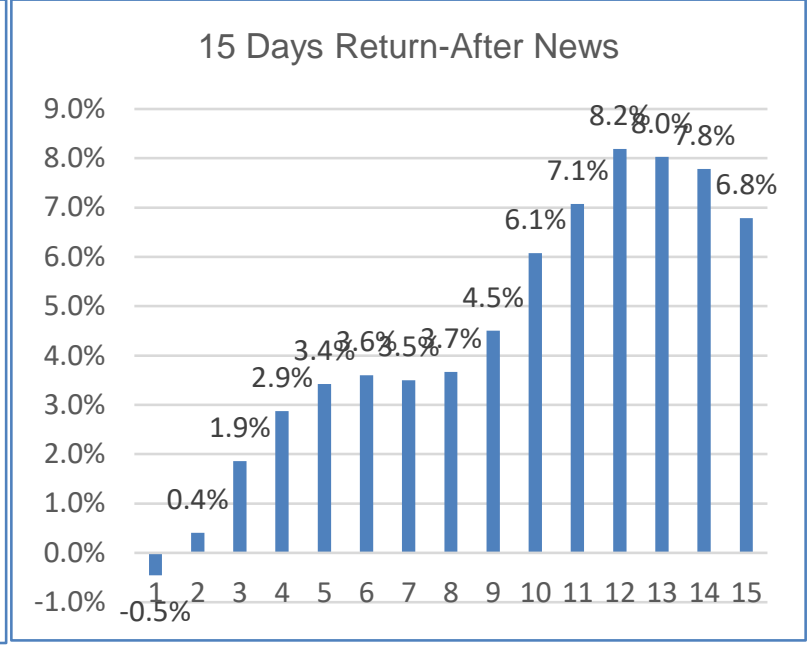

Source: Own

Inspecting Figure 4, it can be seen that the return value of the stock had a negative value only during the first day after the transfer news, with all the other days having positive values. It was thought that there might be a different explanation to this negative value observed for the first day. Since all the returns, including first day returns, were observed to be in a positive direction for 10 and 20-day analyses. Going through the days after transfer news, it was observed that the highest return was obtained on the 12 th day with a value of $8.2 \%$.

The 20-day impact of player transfer news on TSPOR stock is depicted in Figures 5 and 6.

Figure 5: Returns 20 Days Before News Figure 6: Returns 20 Days After News

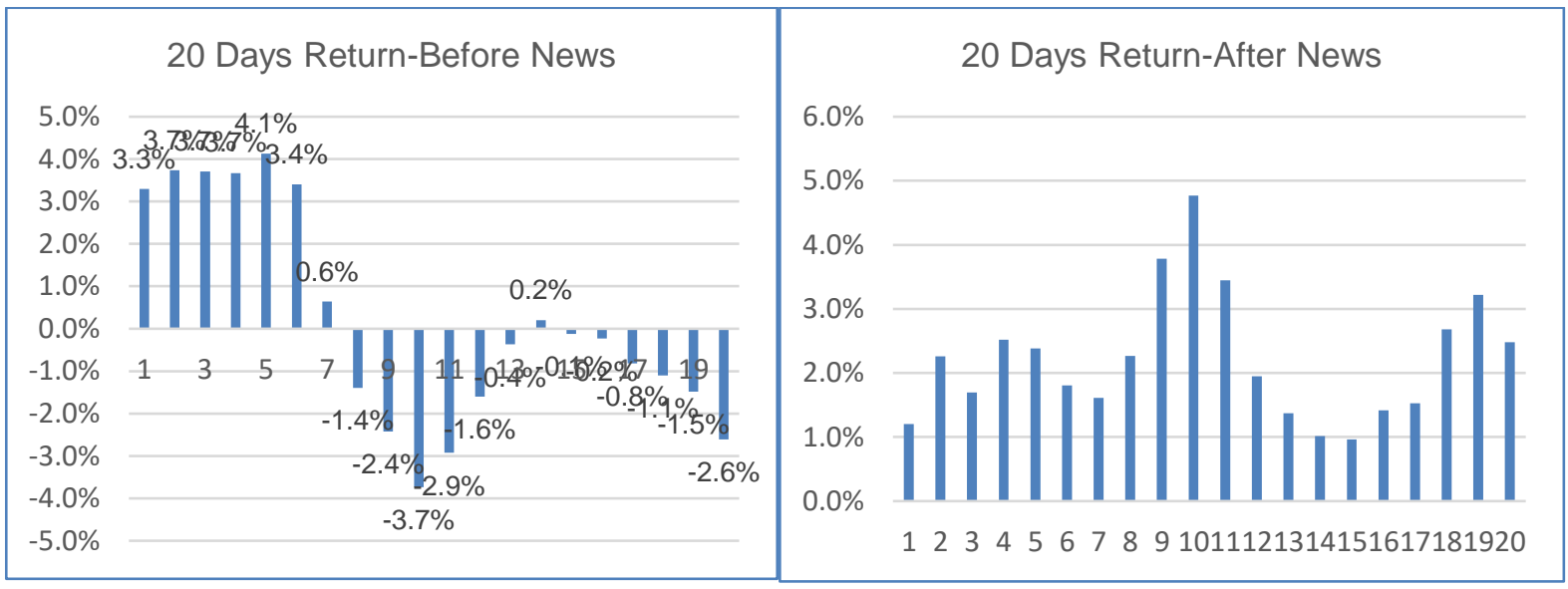

Source: Own

Source: Own

Returns of TSPOR stock experienced a negative trend until the 7th day before the transfer event, except for the 14th day. A positive trend was observed starting on the seventh day and keeping on for the 20-day period after the transfer news. The lowest return was observed on the 10th day before the transfer news with $3.7 \%$, with the 
highest return achieved on the 10th day after the news, with a value of $4.8 \%$. It was thought that the investors relied on the news starting from the 7th day before hearing the news, and those positive developments were effective on the return values of the stock.

Statistical results of event analyses performed by 10, 15 and 20-day return data for evaluating the effect of player transfer news on the returns of TSPOR stock; are provided in Table 3.

Table 3: Statistical Findings for Player Transfer News Event Analyses

\begin{tabular}{l|c|c|c|c|c|c}
\hline \hline \multirow{2}{*}{ Statistical Findings } & \multicolumn{2}{|c|}{ 10 days Return } & \multicolumn{2}{c|}{ 15 days Return } & \multicolumn{2}{c}{ 20 days Return } \\
\cline { 2 - 7 } & Before & After & Before & After & Before & After \\
\hline \hline Average Returns & $0.58 \%$ & $2.44 \%$ & $-0.57 \%$ & $4.49 \%$ & $0.20 \%$ & $2.22 \%$ \\
\hline t-test & 0.438 & 0.012 & 0.560 & 0.078 & 0.306 & 0.122 \\
\hline
\end{tabular}

Source: Own

Studying the results of 10-day analyses, it can be seen that the average return value of $0.58 \%$ of TSPOR stock before the player transfer, increased to a value of $2.44 \%$ after the transfer news. The same situation held true for the 15-day and 20-day return averages. Analyzing the results of 15-day analyses, it was observed that the average return value of $-0.57 \%$ of TSPOR stock before the player transfer increased to a value of $4.49 \%$ after the transfer news; whereas the values increased from $0.20 \%$ to $2.22 \%$ with respect to the 20-day return analyses. Statistical significance of analyses was tested through the t-test. Stock returns calculated after transfer news in 10-day return analyses were found to be significant on a $5 \%$ significance level, whereas stock returns calculated after transfer news in 15-day return analyses were found to be significant on a $10 \%$ significance level.

\subsection{Analysis Results for Head Coach Events}

The 10-day impact of Head Coach related news on the return of TSPOR is provided in Figures 7 and 8.

Returns for stocks were negative for the days when the head coach contract agreements or terminations were realized. Whereas the returns maintained a positive trend after the head coach-related news. Returns of the stock kept increasing till the day 6 of the event, reaching to its peak level at the 10th day with a value of $4.5 \%$. Whereas it demonstrated negative values before the event, having the highest loss on the 10 th day with a value of $-9.3 \%$. 
Figure 7: Returns 10 Days Before News Figure 8:10 Returns 10 Days After News
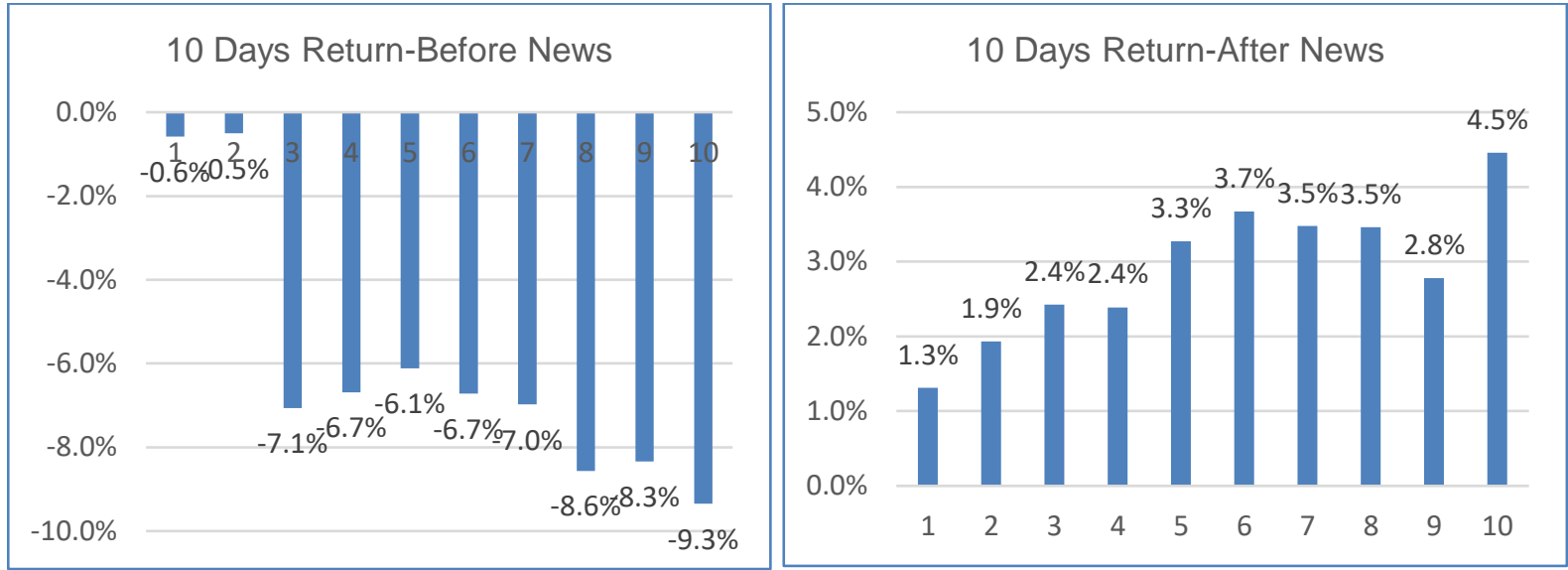

Source: Own Source: Own

The 15-day impact of Head Coach related news on the return of TSPOR is provided in Figures 9 and 10.

\section{Figure 9: Returns 15 Days Before News Figure 10: Returns 15 Days After News}

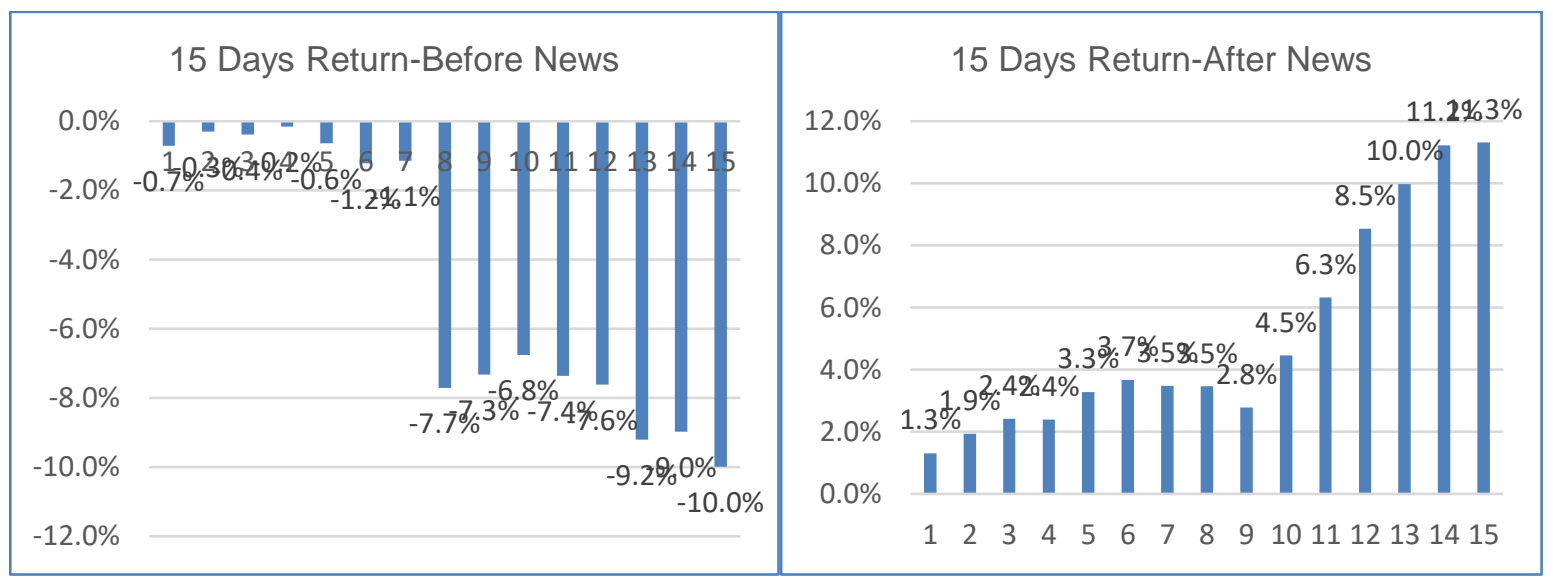

Source: Own Source: Own

Average returns for stocks were observed to be negative for the 15 days before the head coach-related news. The highest loss on the stock was realized on the fifteenth day. A positive trend in average stock was observed after the head coach transfer. The highest return was realized on the fifteenth day. It was thought that the investors reacted either positively or negatively to the news related to head coach replacement.

The 20-day impact of Head Coach related news on the return of TSPOR is provided in Figures 11 and 12. 
Figure 11: Returns 20 Days Before News

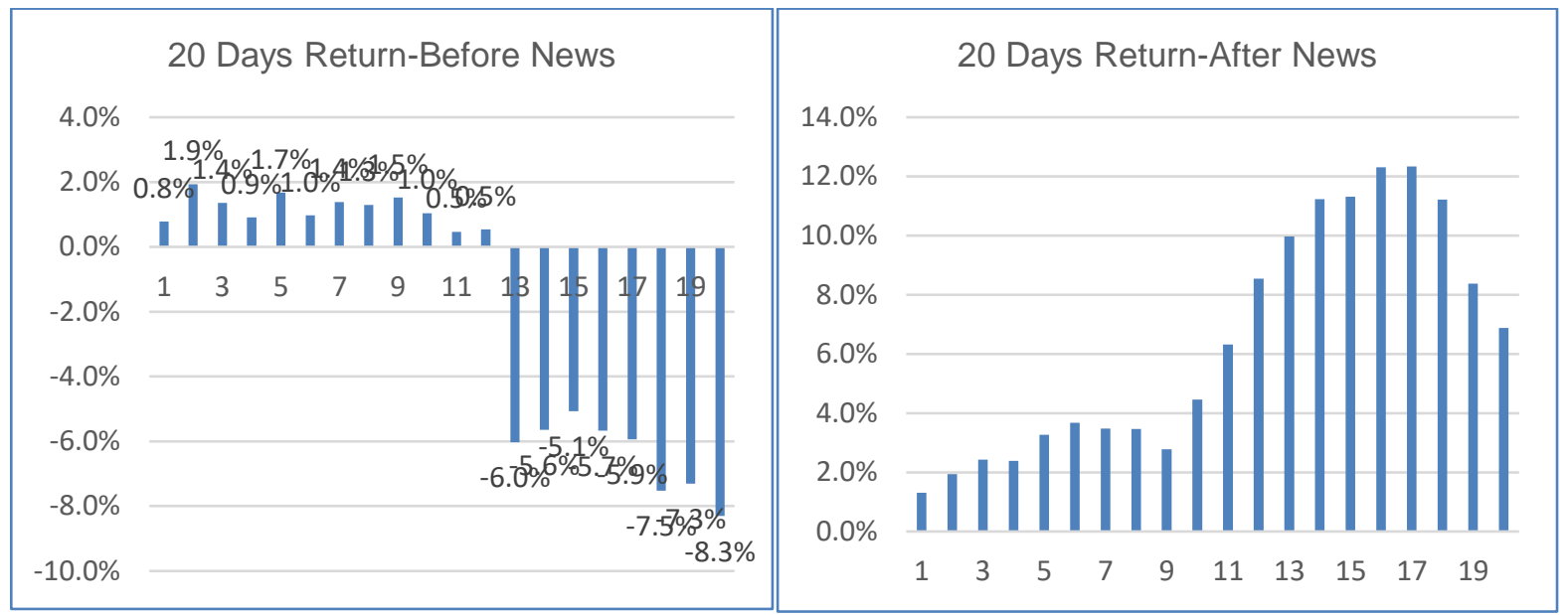

Source: Own

Source: Own

Within the 20-day period before the news related to head coach, the return of stock was observed to be negative until the day 12. The return was positive for the first 12 days prior to replacement of the coach. It was highly surprising that the return was found to be positive. The positive reaction given by investors prior to coach replacement went on for another 20 days after the replacement of the coach.

Statistical results of event analyses performed by 10,15 and 20 day return data for evaluating the effect of head coach related news on the returns of TSPOR stock; are provided in Table 4.

Table 4: Statistical Findings for Head Coach Related News Event Analyses

\begin{tabular}{l|c|c|c|c|c|c}
\hline \hline \multirow{2}{*}{ Statistical Findings } & \multicolumn{2}{|c|}{$\mathbf{1 0}$ days Return } & \multicolumn{2}{c|}{$\mathbf{1 5}$ days Return } & \multicolumn{2}{c}{ 20 days Return } \\
\cline { 2 - 7 } & Before & After & Before & After & Before & After \\
\hline \hline Average Returns & $-6.09 \%$ & $2.93 \%$ & $-4.63 \%$ & $5.11 \%$ & $-1.88 \%$ & $6.39 \%$ \\
\hline t-test & 0.274 & 0.109 & 0.482 & 0.114 & 0.569 & 0.107 \\
\hline
\end{tabular}

Source: Own

Studying the results of 10-day analyses, it can be seen that the value of $-6.09 \%$ effect on returns of TSPOR stock before the coach related news, increased to a value of $2.93 \%$ after the news. The same situation was observed for the 15 and 20-day return analyses. 15-day return analyses revealed an increase in the return value from $-4.63 \%$ before the news to $5.11 \%$; whereas an increase from $-1.88 \%$ to $6.39 \%$ was observed for 20-day analyses. T-test was conducted for determining statistical significance, and $p$ value was not found to be statistically significant for either of these three analyses. 


\section{Conclusions}

There are numerous factors that affect the returns yielded from stocks of football clubs. For this reason, it was thought that the two parameters which have an effect on sportive performance would also have an effect on returns of stocks. Event analyses were conducted considering the news related to football players and head coaches which play a major role regarding the teams' sportive performance and corresponding analyses results were then evaluated. It is of vital importance that a team should have a good team of players along with a good head coach, in order to attain successful results.

10, 15 and 20 day return data was utilized for event analysis method conducted for the evaluation of the effects of player transfer and head coach replacement in Trabzonspor on the returns of stocks, within the period of 2013-2017. Analyses were conducted under two separate categories, namely being player related and head coach related events.

Analysis results were positive 10 days before and after the player transfer news. Whereas the analysis results based on 15-day returns revealed negative returns before the transfer news all through 14 days, except for one day with a positive return. It was observed from the 20-day return analysis of the news related to players, that the return was mostly negative for the period before the news. Regarding the 15 and 20-day analyses, returns were observed to be in a positive direction, except for one day during the period after player transfer news. Football players have a major role regarding the success of football teams. The investors believe that the players would contribute to the team in line with supporters expectations, and the returns of stock would be positively affected by bringing renowned and valuable players of football society in the team. Returns of stocks were observed to have increased after the player transfer news all through the analyses. Evaluating the analyses results with respect to statistical significance, it was determined that only the returns realized after 10 days of news were significant.

Analyses of returns 10 and 15 days before coach related news revealed negative results all through the corresponding period, whereas contrarily, returns were found to be positive after the news. Returns were found to follow a trend starting from the negative proceeding to the positive direction, as the 20-day analyses were evaluated. With respect to the analyses performed by using 20-day return data, it was believed that the investors did not react to coach replacement beforehand. The positive value observed on the return data for 12 days before the news, for the 20-days analyses; despite its negative value obtained by 10 and 15-days analyses, makes one think that the corresponding value might be pricing some other information than the coach related news. Returns were found to be positive all along the analyses after the coach related news. Moreover, it was determined that the coach related news did not have any statistically significant effect on returns of stocks. On the other hand, investors might be affecting stock returns by positively reacting to the concept of coach agreements. Numerous contracts of head coaches were terminated due to 
Trabzonspor's failure to achieve any sportive success during the period of 2013-2017. Sportive failure might cause the stock prices of teams to decline. Whereas the replacement of a coach that is thought to have failed, with a coach that leads the same team to success causes the stock prices to increase. For this reason, it is thought that the coach contracts might have a higher impact on returns of stocks, compared to that of the player contracts. Furthermore, accurate selection of events that might have an effect on stock returns increases the power of the analysis. 
APPENDIX: Analysis Results for Footballer and Head Coach of the Event Study

\begin{tabular}{|c|c|c|c|c|c|c|c|c|c|c|c|}
\hline \multicolumn{6}{|c|}{ Analysis Results for Footballer } & \multicolumn{6}{|c|}{ Analysis Results for Head Coach } \\
\hline Days & Return & Days & Return & Days & Return & Days & Return & Days & Return & Days & Return \\
\hline-10 & $0.20 \%$ & -15 & $0.10 \%$ & -20 & $3.30 \%$ & -10 & $-0.60 \%$ & -15 & $-0.70 \%$ & -20 & $0.80 \%$ \\
\hline-9 & $0.40 \%$ & -14 & $-0.50 \%$ & -19 & $3.70 \%$ & -9 & $-0.50 \%$ & -14 & $-0.30 \%$ & -19 & $1.90 \%$ \\
\hline-8 & $0.70 \%$ & -13 & $-0.90 \%$ & -18 & $3.70 \%$ & -8 & $-7.10 \%$ & -13 & $-0.40 \%$ & -18 & $1.40 \%$ \\
\hline-7 & $0.60 \%$ & -12 & $-0.90 \%$ & -17 & $3.70 \%$ & -7 & $-6.70 \%$ & -12 & $-0.20 \%$ & -17 & $0.90 \%$ \\
\hline-6 & $0.60 \%$ & -11 & $-1.10 \%$ & -16 & $4.10 \%$ & -6 & $-6.10 \%$ & -11 & $-0.60 \%$ & -16 & $1.70 \%$ \\
\hline-5 & $0.60 \%$ & -10 & $-0.90 \%$ & -15 & $3.40 \%$ & -5 & $-6.70 \%$ & -10 & $-1.20 \%$ & -15 & $1.00 \%$ \\
\hline-4 & $0.60 \%$ & -9 & $-0.70 \%$ & -14 & $0.60 \%$ & -4 & $-7.00 \%$ & -9 & $-1.10 \%$ & -14 & $1.40 \%$ \\
\hline-3 & $1.00 \%$ & -8 & $-0.40 \%$ & -13 & $-1.40 \%$ & -3 & $-8.60 \%$ & -8 & $-7.70 \%$ & -13 & $1.30 \%$ \\
\hline-2 & $0.80 \%$ & -7 & $-0.50 \%$ & -12 & $-2.40 \%$ & -2 & $-8.30 \%$ & -7 & $-7.30 \%$ & -12 & $1.50 \%$ \\
\hline-1 & $0.30 \%$ & -6 & $-0.50 \%$ & -11 & $-3.70 \%$ & -1 & $-9.30 \%$ & -6 & $-6.80 \%$ & -11 & $1.00 \%$ \\
\hline 1 & $1.20 \%$ & -5 & $-0.50 \%$ & -10 & $-2.90 \%$ & 1 & $1.30 \%$ & -5 & $-7.40 \%$ & -10 & $0.50 \%$ \\
\hline 2 & $2.30 \%$ & -4 & $-0.50 \%$ & -9 & $-1.60 \%$ & 2 & $1.90 \%$ & -4 & $-7.60 \%$ & -9 & $0.50 \%$ \\
\hline 3 & $1.70 \%$ & -3 & $-0.10 \%$ & -8 & $-0.40 \%$ & 3 & $2.40 \%$ & -3 & $-9.20 \%$ & -8 & $-6.00 \%$ \\
\hline 4 & $2.50 \%$ & -2 & $-0.30 \%$ & -7 & $0.20 \%$ & 4 & $2.40 \%$ & -2 & $-9.00 \%$ & -7 & $-5.60 \%$ \\
\hline 5 & $2.40 \%$ & -1 & $0.80 \%$ & -6 & $-0.10 \%$ & 5 & $3.30 \%$ & -1 & $-10.00 \%$ & -6 & $-5.10 \%$ \\
\hline 6 & $1.80 \%$ & 1 & $-0.50 \%$ & -5 & $-0.20 \%$ & 6 & $3.70 \%$ & 1 & $1.30 \%$ & -5 & $-5.70 \%$ \\
\hline 7 & $1.60 \%$ & 2 & $0.40 \%$ & -4 & $0.80 \%$ & 7 & $3.50 \%$ & 2 & $1.90 \%$ & -4 & $-5.90 \%$ \\
\hline 8 & $2.30 \%$ & 3 & $1.90 \%$ & -3 & $-1.10 \%$ & 8 & $3.50 \%$ & 3 & $2.40 \%$ & -3 & $-7.50 \%$ \\
\hline 9 & $3.80 \%$ & 4 & $2.90 \%$ & -2 & $-1.50 \%$ & 9 & $2.80 \%$ & 4 & $2.40 \%$ & -2 & $-7.30 \%$ \\
\hline 10 & $4.80 \%$ & 5 & $3.40 \%$ & -1 & $-2.60 \%$ & 10 & $4.50 \%$ & 5 & $3.30 \%$ & -1 & $-8.30 \%$ \\
\hline & & 6 & $3.60 \%$ & 1 & $1.20 \%$ & & & 6 & $3.70 \%$ & 1 & $1.30 \%$ \\
\hline & & 7 & $3.50 \%$ & 2 & $2.30 \%$ & & & 7 & $3.50 \%$ & 2 & $1.90 \%$ \\
\hline & & 8 & $3.70 \%$ & 3 & $1.70 \%$ & & & 8 & $3.50 \%$ & 3 & $2.40 \%$ \\
\hline & & 9 & $4.50 \%$ & 4 & $2.50 \%$ & & & 9 & $2.80 \%$ & 4 & $2.40 \%$ \\
\hline & & 10 & $6.10 \%$ & 5 & $2.40 \%$ & & & 10 & $4.50 \%$ & 5 & $3.30 \%$ \\
\hline & & 11 & $7.10 \%$ & 6 & $1.80 \%$ & & & 11 & $6.30 \%$ & 6 & $3.70 \%$ \\
\hline & & 12 & $8.20 \%$ & 7 & $1.60 \%$ & & & 12 & $8.50 \%$ & 7 & $3.50 \%$ \\
\hline & & 13 & $8.00 \%$ & 8 & $2.30 \%$ & & & 13 & $10.00 \%$ & 8 & $3.50 \%$ \\
\hline & & 14 & $7.80 \%$ & 9 & $3.80 \%$ & & & 14 & $11.20 \%$ & 9 & $2.80 \%$ \\
\hline & & 15 & $6.80 \%$ & 10 & $4.80 \%$ & & & 15 & $11.30 \%$ & 10 & $4.50 \%$ \\
\hline & & & & 11 & $3.40 \%$ & & & & & 11 & $6.30 \%$ \\
\hline & & & & 12 & $1.90 \%$ & & & & & 12 & $8.50 \%$ \\
\hline & & & & 13 & $1.40 \%$ & & & & & 13 & $10.00 \%$ \\
\hline & & & & 14 & $1.00 \%$ & & & & & 14 & $11.20 \%$ \\
\hline & & & & 15 & $1.00 \%$ & & & & & 15 & $11.30 \%$ \\
\hline & & & & 16 & $1.40 \%$ & & & & & 16 & $12.30 \%$ \\
\hline & & & & 17 & $1.50 \%$ & & & & & 17 & $12.30 \%$ \\
\hline & & & & 18 & $2.70 \%$ & & & & & 18 & $11.20 \%$ \\
\hline & & & & 19 & $3.20 \%$ & & & & & 19 & $8.40 \%$ \\
\hline & & & & 20 & $2.50 \%$ & & & & & 20 & $6.90 \%$ \\
\hline
\end{tabular}




\section{References}

Barajas, a., Fernández-Jardón, c. m., \& Crolley, I. (2005). Does sports performance influence revenues and economic results in Spanish football ?. MPRA Paper No.: 3234.

Becchetti, L., Ciciretti, R. \& Hasan, I. (2007). Corporate social responsibility and shareholder's value: An event study analysis. Working Paper, Federal Reserve Bank of Atlanta, No. 2007-6, Federal Reserve Bank of Atlanta, Atlanta, GA.

Bell, A., Brooks, C., \& amp; Markham, T. (2013). Does managerial turnover affect football club share prices ?. Aestimatio, the IEB International Journal of Finance, 7, 02-21.

Bell, a. r., Brooks, c., Matthews, d., \& Sutcliffe, a. (2012). Over the moon or sick as a parrot? The effects of football on a club's share price. Applied Economics, 44(26), 3435-3452.

Binder, JJ (1998). The Event Study Methodology Since 1969. Review of Quantitative Finance and Accounting, 11, 111-137.

de Dios Tena, j., \& Forrest, b. (2007). Within-season dismissal of football coaches: Statistical analysis of causes and consequences. European Journal of Operational Research, 181(1), 362-373.

Dedman, E., \& Lin, SWJ (2002). Shareholder wealth effects of CEO departments: Evidence from the UK. Journal of Corporate Finance, 8(1), 81-104.

Dyckman, t., Pahari, d., \& Stephan, j. (1984). A Comparison of Event Study Methodologies Using Daily Stock Returns: A Simulation Approach. Journal of Accounting Research, 22, 1-30.

Farah, P., Li, (M.) H., \& Nguyen, L. (2015). CEO Turnover: Transparency of Announcements and the Outperformance Puzzle. Available at SSRN: https://ssrn.com/abstract=2647838 or http://dx.doi.org/10.2139/ssrn.2647838

Fotaki, M., Markellos, RN, \& Mania, M. (2009). Human resources turnover is an asset acquisition, accumulation and divesture process. Athens University of Economics and Business, Working Paper.

Gimet, c., \& Montchaud, s. (2016). What Drives European Football Clubs' Stock Returns and Volatility ?. International Journal of the Economics of Business, 23(3), 351-390.

Goal.com (2017). http://www.goal.com/en/news/revealed-how-much-real-madrid-and-barcelona-willearn-from/10mo6oe3tcyan15j6u2e2kcr8t (Access Date: 04/21/2018).

Godinho, p., \& Cerqueira, p. (2018). The impact of expectations, match importance, and results in European football teams. Journal of Sports Economics, 19(2), 230-278.

González-Gómez, f., Picazo-Tadeo, a. j., \& García-Rubio, m. Á. (2011). The impact of a mid-season change of manager on sporting performance. Sport, Business and Management: An International Journal, 1(1), 28-42.

Heuer, A., Müller, C., Rubner, O., Hagemann, N., \& Strauss, B. (2011). Usefulness of are dismissing and changing the coach of professional soccer. PloS one, 6(3), E17664.

Kırkulak Uludağ, B., \& Sigalı, S. (2016). Football match Results 4 Adults Stock I effect. Ege Academic Review, 16(4).

Kind, A., \& Schläpfer, Y. (2010). Is a CEO turnover good or bad news (No. 2010/13). 
Peterson, PP (1989). Event Studies: A Review of Issues and Methodology. Quarterly Journal of Business and Economics, 28 (3), 36-66.

Serra, Ana Paula. (2004). Event Study Tests: A Brief Survey. Gestão.Org-Revista Electrónica de Gestão Organizacional, 2nd(3), 248-255.

Scholtens, B., \& Peenstra, W. (2009). Scoring on the stock exchange? The effect of football matches on stock market returns: an event study. Applied Economics, 41(25), 3231-3237.

UEFA (2018). Club Licensing Benchmarking Report Financial Year 2016, https://www.uefa.com/multimediafiles/download/officialdocument/uefaorg/clublicensing/02/53/00/ 22/2530022 download.pdf (Access Date: 04/21/2018).

The Telegraph (2018). https://www.telegraph.co.uk/football/2018/02/28/arsenals-operating-profits-fall60-per-cent-missing-champions/ (Access Date: 04/21/2018).

TransferMarkt

(2018).

http://www.transfermarkt.com.tr/superlig/transferausgabentabellenplatz/wettbewerb/tr1 (Date of Access: 04/22/2018).

Total Sportek (2018). https://www.totalsportek.com/money/uefa-champions-league-prize-money/ (Access Date: 04/21/2018).

Zeren, F., \& Gümüş, F. B. (2013). An application on the stock market performances of Turkish and foreign football teams. Çankırı Karatekin University IIIBF Magazine, 3(2), 34-54.

Zuber, r. a., Yiu, p., Lamb, r. p., \& Gandar, j. m. (2005). Investor - fans? An examination of the publicly traded English Premier League teams. Applied Financial Economics, 15(5), 305-313. 